\title{
Presepsin and Prognostic Nutritional Index are predictors of septic acute kidney injury, renal replacement therapy initiation in sepsis patients, and prognosis in septic acute kidney injury patients: a pilot study
}

Yuichiro Shimoyama ( $\square$ shimocchiliebesfreud512@yahoo.co.jp )

Osaka Medical College

Osamu Umegaki

Osaka Medical College: Osaka Ika Daigaku

Noriko Kadono

Osaka Medical College: Osaka Ika Daigaku

Toshiaki Minami

Osaka Medical College: Osaka Ika Daigaku

Research article

Keywords: presepsin, sepsis, sepsis-3 definition, inflammation-based prognostic scores, acute kidney injury, renal replacement therapy

Posted Date: April 1st, 2021

DOl: https://doi.org/10.21203/rs.3.rs-366947/v1

License: (c) (1) This work is licensed under a Creative Commons Attribution 4.0 International License. Read Full License 


\section{Abstract \\ Background}

Sepsis is the most common cause of acute kidney injury (AKI) among critically ill patients. This study aimed to determine whether presepsin is a predictor of septic acute kidney injury, renal replacement therapy initiation (RRTi) in sepsis patients, and prognosis in septic AKI patients.

\section{Methods}

Presepsin values were measured immediately after ICU admission (baseline) and on Days 2, 3, and 5 after ICU admission. Glasgow Prognostic Score (GPS), neutrophil to lymphocyte ratio (NLR), platelet to lymphocyte ratio, Prognostic Index, and Prognostic Nutritional Index (PNI) were measured at baseline. Total scores were calculated (hereafter, "inflammation-presepsin scores [iPS]") for category classification. Presepsin values, inflammation-based prognostic scores, and iPS were compared between patients with and without septic AKI or RRTi and between survivors and non-survivors.

\section{Results}

Receiver operating characteristic curve analyses identified the following variables as predictors of septic AKI and RRTi in sepsis patients: presepsin on Day 1 (AUC: 0.73) and Day 2 (AUC: 0.71) for septic AKI, and presepsin on Day 1 (AUC: 0.71), Day 2 (AUC: 0.9), and Day 5 (AUC: 0.96), $\triangle$ presepsin (Day 2 - Day 1) (AUC: 0.84), $\Delta$ presepsin (Day 5 - Day 1) (AUC: 0.93), and PNI (AUC: 0.72) for RRTi. Multivariate logistic regression analyses identified presepsin on Day 2 as a predictor of prognosis in septic AKI patients.

\section{Conclusions}

Presepsin and PNI were found to be predictors of septic AKI, RRTi in sepsis patients, and prognosis in septic AKI patients.

\section{Background}

Sepsis is the main cause of mortality in critically ill intensive care unit (ICU) patients [1], and new sepsis criteria were established in 2016 [2]. Sepsis is the most common cause of acute kidney injury (AKI) among critically ill patients [3]. Early treatment with appropriate antibiotics improves the prognosis and survival of severe sepsis and septic shock patients [4-6].

Procalcitonin (PCT) is the main biomarker used to diagnose sepsis [7], but its values increase in nonsepsis pathologies as well [8-10]. Presepsin is a subtype of soluble CD14 (CD14-ST) [11], and is an accurate biomarker for diagnosing sepsis. Presepsin has a higher specificity for sepsis diagnosis 
compared with PCT and IL-6 [12], and thus could be useful for the prognosis of sepsis and monitoring the course of the disease [13]. Another advantage of presepsin is that it can be measured in less than 17 minutes with a compact fully automated immunoanalyzer (PATHFAST®; Mitsubishi Chemical Medience Corporation, Tokyo, Japan) [14].

The Glasgow Prognostic Score (GPS; based on serum C-reactive protein (CRP) and albumin levels), neutrophil to lymphocyte ratio (NLR), platelet to lymphocyte ratio (PLR), Prognostic Nutritional Index (PNl; based on albumin and lymphocyte counts), and the Prognostic Index (PI; based on serum CRP and white blood cell counts), are inflammation-based prognostic scores which are useful prognostic biomarkers for many types of cancer [15]. However, no study has investigated the association of septic acute kidney injury (AKI), renal replacement therapy initiation (RRTi), and prognosis of septic AKI with presepsin values alone or in combination with the above-mentioned inflammation-based prognostic scores in septic ICU patients.

The present study aimed to prove the following hypotheses: 1 ) presepsin can predict septic AKI, RRTi in sepsis ICU patients, and prognosis in septic AKI ICU patients; and 2) the ability of presepsin to predict the above are superior to inflammation-based prognostic scores and can be improved by combining presepsin values with inflammation-based prognostic scores.

\section{Methods}

\section{Patients and study design}

The study design, inclusion and exclusion criteria, and definition of "inflammation-presepsin scores [iPS]" used in the present study were published previously [16]. Septic AKI was defined as stage $\geq 1$ kidney disease according to the Kidney Disease: Improving Global Outcomes (KDIGO) classification [17]. Presepsin values, inflammation-based prognostic scores, iPS, and changes $(\Delta)$ in presepsin values relative to baseline values at each sampling point were compared between patients with and without septic AKI or RRTi and between survivors and non-survivors.

\section{Laboratory assessments}

Presepsin concentration was measured by PATHFAST ${ }^{\circledR}$ (Mitsubishi Chemical Medience Corporation, Tokyo, Japan) [14]. Threshold values were as follows: (a) 300 to $500 \mathrm{pg} / \mathrm{ml}$ : "systemic infection (sepsis) possible"; (b) 500 to $1000 \mathrm{pg} / \mathrm{ml}$ : "significant risk of systemic infection progression (severe sepsis), increased risk of unfavorable outcome"; and (c) $\geq 1000 \mathrm{pg} / \mathrm{ml}$ : "High risk of systemic infection progression (severe sepsis/septic shock). High risk for mortality after 30 day comparable with a SOFA score $\geq 8$ " $[18,19]$.

\section{Statistical analysis}

Categorical data are reported as percentages and compared using Fisher's exact test. Continuous data are reported as medians with inter-quartile ranges and compared using the Mann-Whitney U test. ROC 
curves were generated for presepsin values, inflammation-based prognostic scores, iPS, and $\Delta$ presepsin, and areas under the curve (AUCs), cut-off values, sensitivities, and specificities were calculated. For all values of presepsin, inflammation-based prognostic scores, iPS, and $\Delta$ presepsin, Kaplan-Meier curves were constructed for each mortality category, and the log-rank test was performed. Presepsin values on Day 1 and Day 2, inflammation-based prognostic scores, and iPS were examined further by multivariate logistic regression analysis for septic AKI, RRTi in sepsis patients, and prognosis in septic AKI patients. $P$ $<0.05$ was considered statistically significant. JMP software version 11.00 (SAS Institute Inc., NC, USA) was used for all statistical analyses.

\section{Results}

Baseline characteristics of 83 adult patients diagnosed with sepsis according to the Sepsis-3 definition and admitted to the ICU are shown in Table 1. Median age was 74 years (range: 65.5-78.5). No significant differences were observed in age and sex in septic AKI patients and RRTi patients (Table 2).

There were 38 septic AKI patients defined as stage $\geq 1$ according to the KDIGO classification, and 6 patients who underwent RRTi after ICU admission. ROC curve analyses revealed the following cut-off values (Table 3): AKI: 708.0 (pg/ml) for presepsin on Day 1 (AUC, 0.73 ; sensitivity, $81.6 \%$; specificity, $58.5 \%$ ) and 985.0 (pg/ml) for presepsin on Day 2 (AUC, 0.71; sensitivity, 65.5\%; specificity, 64.3\%); RRTi: 2014.0 (pg/ml) for presepsin on Day 1 (AUC, 0.71; sensitivity, 66.7\%; specificity, 83.3\%), 2867.0 (pg/ml) for presepsin on Day 2 (AUC, 0.90; sensitivity, 75.0\%; specificity, 91.7\%), 3014.0 (pg/ml) for presepsin on Day 5 (AUC, 0.96; sensitivity, 100.0\%; specificity, 92.9\%), 507.0 (pg/ml) for $\Delta$ presepsin (Day 2 - Day 1) (AUC, 0.84; sensitivity, 75.0\%; specificity, 80.0\%), 2385.0 (pg/ml) for $\Delta$ presepsin (Day 5 - Day 1) (AUC, 0.93; sensitivity, $100.0 \%$; specificity, $93.3 \%$ ), and 19.5 for PNI (AUC, 0.72 ; sensitivity, $66.7 \%$; specificity, 93.5\%). Regarding prognosis in septic AKI patients, the results of ROC curve analyses, Log-rank test, and univariate analysis are shown in Tables 4, 5, and 6, respectively.

We also performed multivariate logistic regression analyses to identify independent predictors of septic AKI, RRTi in septic patients, and prognosis in septic AKI patients (Table 7). Multivariate logistic regression analyses revealed that presepsin on Day 2 is a predictor of prognosis in septic AKI patients.

\section{Discussion}

Sepsis involves lethal organ dysfunction due to the activation of both pro- and anti-inflammatory responses [20], and is modified by non-immunologic pathways, including cardiovascular, neuronal, autonomic, hormonal, bioenergetic, metabolic, and coagulation pathways [21-23]. Severe sepsis is associated with a mortality rate of $>50 \%$ [24], and the most common cause of AKI among critically ill patients is sepsis [3]. PCT has the highest specificity among diagnostic markers for sepsis, but can yield false positive results since its levels increase in various non-sepsis contexts (e.g., severe trauma, invasive surgical procedure, critical burn injuries) [8-10]. Presepsin, another diagnostic marker for sepsis, is secreted from granulocytes in response to infectious stimuli in an animal sepsis model [25]. According to 
Liu et al., presepsin was the best predictor of early stage sepsis in emergency department patients [26]. Presepsin values have also been reported to be associated with organ dysfunction, coagulation disorders, and ICU mortality [27].

In the present study, presepsin cut-off values for predicting septic AKI, RRTi in sepsis patients, and prognosis in septic AKI patients were higher than those previously reported as predicting severe sepsis and septic shock $[18,19]$ (Tables 3, 4$)$. Moreover, presepsin values for predicting RRTi had a higher cutoff value and specificity relative to those for predicting septic AKI. A significant negative correlation was previously reported between presepsin levels and estimated glomerular filtration rate in both non-sepsis and sepsis patients [28]. Increases in presepsin levels in hemodialysis (HD) patients may not be related to renal dysfunction, but rather the activation of neutrophils and/or monocytes, since HD activates monocytes and/or neutrophils, which in turn leads to presepsin release from monocytes [29]. Presepsin levels in HD patients without infection were reported to be $783-2,360 \mathrm{pg} / \mathrm{ml}$ [30]. Nakamura et al. retrospectively examined presepsin values in ICU patients with or without sepsis, and reported that presepsin values were markedly high in patients with renal failure and end-stage kidney disease. Presepsin values in those with sepsis ranged from 2,632 to $20,000 \mathrm{pg} / \mathrm{ml}$, while patients without sepsis had presepsin values of 2,134 to $19,633 \mathrm{pg} / \mathrm{ml}$ [28]. In the present study, presepsin cut-off values for predicting RRTi were similar to these previously reported levels. Our results suggest the need to adopt a higher presepsin cut-off value for predicting septic AKI, RRTi in sepsis patients, and prognosis in septic AKI patients.

Cut-off values for predicting septic AKI, RRTi in sepsis patients, and prognosis in septic AKI patients on Day 2 or later after ICU entry were higher than those on Day 1 (Tables 3,4$)$. Multivariate logistic regression analyses identified presepsin on Day 2 to be a predictor of prognosis in septic AKI patients (Table 7). Presepsin levels measured at the time of ICU admission may not be at an optimal level for predicting septic AKI, RRTi in sepsis patients, and prognosis in septic AKI patients. Indeed, several studies have reported that presepsin levels increase as the severity of sepsis increases [31-33]. For instance, Masson et al. reported that an increase in presepsin levels from Day 1 to Day 2 after ICU admission can predict higher ICU and 90-day mortality [34]. Our findings suggest the importance of not only measuring presepsin levels at the time of ICU admission, but also monitoring its temporal changes after ICU admission in order to better predict the onset of septic AKI, RRTi in sepsis patients, and prognosis in septic AKI patients.

The AUC, sensitivity, and specificity of PNI for predicting RRTi were $0.72,66.7 \%$, and $93.5 \%$, respectively, with a higher specificity than that for presepsin alone on Days 1, 2, and 5. The corresponding median PNI values (inter-quartile range) were 18.4 (14.6-30.0) in RRTi patients and 28.9 (22.7-34.1) in non-RRTi patients. These findings suggest that a lower PNI can predict RRTi in sepsis patients and may serve as an easy "rule in" test at the time of ICU admission. PNI can be obtained at low cost and rapidly in clinical settings where presepsin values cannot be easily measured, and provides information necessary for interventions in sepsis patients within the first few hours of ICU admission. Our findings also suggest that hypoalbuminemia and lymphocytopenia (albumin and lymphocyte counts are used to calculate PNI) are 
important variables for predicting RRTi in sepsis patients. Serum albumin levels are significantly correlated with presepsin levels [30]. Zahorec et al. found a correlation between severity of the clinical course and extent of lymphocytopenia in oncological ICU patients following major surgery, sepsis, and septic shock [35].

This study has several limitations. First, the present study was conducted at a single center with a small sample size. Second, we used a single biomarker, and no comparisons were made with other biomarkers.

\section{Conclusions}

Presepsin and PNI were found to be predictors of septic AKI, RRTi in sepsis patients, and prognosis in septic AKI patients. Cut-off values and specificities for predicting septic AKI and RRTi on Day 2 or later were higher than those on Day 1. Further studies aimed at understanding the exact role of presepsin values and PNI in predicting septic AKI, RRTi in sepsis patients, and prognosis in septic AKI patients are warranted.

\section{Abbreviations}

GPS: Glasgow Prognostic Score, CRP: C-reactive protein, NLR: neutrophil to lymphocyte ratio, PLR: platelet to lymphocyte ratio, PNI: Prognostic Nutritional Index, PI: Prognostic Index, SOFA: Sequential Organ Failure Assessment, qSOFA: quick Sequential Organ Failure Assessment, ROC: Receiver operating characteristic, AUC: area under the curve; RRTi: renal replacement therapy initiation; AKI: acute kidney injury, HD: hemodialysis

\section{Declarations}

Ethics approval and consent to participate: The study protocol was approved by the Ethics Committee of Osaka Medical College (\#2206; Osaka, Japan). Written Informed consent was obtained from all patients enrolled in this study or their families.

Consent for publication: Not applicable.

Availability of data and materials: The datasets used and/or analyzed during the current study are available from the corresponding author on reasonable request.

Competing interests: The authors declare that they have no competing interests.

Funding: Not applicable.

Authors' contributions: YS designed the study, collected the data, performed the statistical analysis, and wrote the first draft of the manuscript. OU, NK, and TM designed the study and revised the manuscript. All authors read and approved the final manuscript. 
Acknowledgements: Not applicable.

\section{References}

1. Singer M, Deutschman CS, Seymour CW, Shankar-Hari M, Annane D, Bauer M, et al. The third international consensus definitions for sepsis and septic shock (Sepsis-3). JAMA. 2016;315:801-10.

2. Vincent JL, Sakr Y, Sprung CL, Ranieri VM, Reinhart K, Gerlach H, et al. Sepsis in European intensive care units: results of the SOAP study. Crit Care Med. 2006;34:344-53.

3. Murugan R, Kellum JA. Acute kidney injury: what's the prognosis? Nat Rev Nephrol. 2011;7:209-17.

4. Battleman DS, Callahan M, Thaler HT. Rapid antibiotic delivery and appropriate antibiotic selection reduce length of hospital stay of patients with community-acquired pneumonia: link between quality of care and resource utilization. Arch Intern Med. 2002;162:682-8.

5. Kumar A, Roberts D, Wood KE, Light B, Parrillo JE, Sharma S, et al. Duration of hypotension before initiation of effective antimicrobial therapy is the critical determinant of survival in human septic shock. Crit Care Med. 2006;34:1589-96.

6. Rivers E, Nguyen B, Havstad S, Ressler J, Muzzin A, Knoblich B, et al. Early goal-directed therapy in the treatment of severe sepsis and septic shock. N Engl J Med. 2001;345:1368-77.

7. Herzum I, Renz H. Inflammatory markers in SIRS, sepsis and septic shock. Curr Med Chem. 2008;15:581-7.

8. Pierrakos C, Vincent J-L: Sepsis biomarkers: a review. Crit Care 14:R15, 2010.

9. Wacker C, Prkno A, Brunkhorst FM, Schlattmann P: Procalcitonin as a diagnostic marker for sepsis: a systematic review and meta-analysis. Lancet Infect Dis 13:426-35, 2013.

10. Kibe S, Adams K, Barlow G. Diagnostic and prognostic biomarkers of sepsis in critical care. J Antimicrob Chemother. 2011;66(Suppl 2):ii33-40.

11. Shirakawa K, Naitou K, Hirose J, Takahashi T, Furusako S: Presepsin (sCD14-ST): development and evaluation of one-step ELISA with a new standard that is similar to the form of presepsin in septic patients. Clin Chem Lab Med 2011, 49:937-939.

12. Endo S, Suzuki Y, Takahashi G, Shozushima T, Ishikura H, Murai A, et al. Usefulness of presepsin in the diagnosis of sepsis in a multicenter prospective study. J Infec Chemother Official J Japan Soc Chemotherap 2012, 18:891-897.

13. Shozushima T, Takahashi G, Matsumoto N, Kojika M, Okamura Y, Endo S. Usefulness of presepsin (sCD14-ST) measurements as a marker for the diagnosis and severity of sepsis that satisfied diagnostic criteria of systemic inflammatory response syndrome. J Infect Chemother. 2011;17:7649.

14. Okamura Y, Yokoi H. Development of a point-of-care assay system for measurement of presepsin (sCD14-ST). Clin Chim Acta. 2011;412:2157-61.

15. Kinoshita A, Onoda H, Imai N, A Iwaku, M Oishi, N Fushiya, et al: Comparison of the prognostic value of inflammation-based prognostic scores in patients with hepatocellular carcinoma. Br J Cancer 
2012; 107:988-993

16. Yuichiro Shimoyama, Osamu Umegaki, Noriko Kadono, Toshiaki Minami. Presepsin Values Predict Septic Acute Kidney Injury, Acute Respiratory Distress Syndrome, Disseminated Intravascular Coagulation, and Shock. Shock 2020; doi: 10.1097/SHK.0000000000001664. Online ahead of print.

17. KDIGO Guideline. Kidney disease: Improving global outcomes. Clinical practice guideline on acute kidney injury 2011. http://www.kdigo.org. Accessed 4 April 2012.

18. C. Chenevier-Gobeaux, D. Borderie, N. Weiss, T. Mallet-Coste and Y.-E. Claessens, "Presepsin (sCD14ST), an innate immune response marker in sepsis," Clinica chimica acta; international journal of clinical chemistry, vol. 450, p. 97-103, 2015.

19. R. Carpio, J. Zapata, E. Spanuth and G. Hess, “Utility of presepsin (sCD14-ST) as a diagnostic and prognostic marker of sepsis in the emergency department," Clinica chimica acta; international journal of clinical chemistry, vol. 450, p. 169-175, 2015.

20. Hotchkiss RS, Monneret G, Payen D. Sepsis-induced immunosuppression: from cellular dysfunctions to immunotherapy. Nat Rev Immunol. 2013; 13(12):862-874.

21. Levy MM, Fink MP, Marshall JC, Abraham E, Angus D, Cook D, et al. SCCM/ESICM/ACCP/ATS/SIS international sepsis definitions conference. Intensive Care Med 2001, 2003(29):530-538.

22. Calandra T, Cohen J: The international sepsis forum consensus conference on definitions of infection in the intensive care unit. Crit Care Med 2005, 33:1538-1548.

23. Tunkel AR, Hartman BJ, Kaplan SL, Kaufman BA, Roos KL, Scheld WM, et al. Practice guidelines for the management of bacterial meningitis. Clin Infect Dis 2004, 39:1267-1284.

24. Angus DC, Linde-Zwirble WT, Lidicker J, Clermont G, Carcillo J, Pinsky MR: Epidemiology of severe sepsis in the United States: analysis of incidence, outcome and associated costs of care. Crit Care Med 2001, 29:1303-1310.

25. Naitoh K, Shirakawa K, Hirose J, Nakamura M, Takeuchi T, Hosaka Y, et al. The new sepsis marker, SCD14-ST (PRESEPSIN): induction mechanism in the rabbit sepsis models. Crit Care 2010, 14:P19.

26. Liu B, Chen Y-X, Yin Q, Zhao Y-Z, Li C-S. Diagnostic value and prognostic evaluation of Presepsin for sepsis in an emergency department. Crit Care. 2013; 17(5):R244.

27. Masson S, Caironi P, Fanizza C, Thomae R, Bernasconi R, Noto A, et al. Circulating presepsin (soluble CD14 subtype) as a marker of host response in patients with severe sepsis or septic shock: data from the multicenter, randomized ALBIOS trial. Intensive Care Med. 2015; 41:12-20.

28. Nakamura Y, Ishikura H, Nishida T, Kawano Y, Yuge R, Ichiki R, et al. Usefulness of presepsin in the diagnosis of sepsis in patients with or without acute kidney injury. BMC Anesthesiol. 2014;14:88.

29. Takahashi G, Shibata S, Fukui Y, Okamura Y, Inoue Y. Diagnostic accuracy of procalcitonin and presepsin for infectious disease in patients with acute kidney injury. Diagn Microbiol Infect Dis. 2016 Oct; 86(2):205-10.

30. Takanobu Nagata, Yoshinari Yasuda, Masahiko Ando, Tomoko Abe, Takayuki Katsuno, Sawako Kato, et al. Clinical Impact of Kidney Function on Presepsin Levels. PLoS One. 2015 Jun 1; 
10(6):e0129159. doi: 10.1371/journal.pone.0129159.

31. T. Shozushima, G. Takahashi, N. Matsumoto, M. Kojika, Y. Okamura, S. Endo, Usefulness of presepsin (sCD14-ST) measurements as a marker for the diagnosis and severity of sepsis that satisfied diagnostic criteria of systemic inflammatory response syndrome, J. Infect. Chemother. 17 (2011) 764-769.

32. B. Liu, Y.X. Chen, Q. Yin, Y.Z. Zhao, C.S. Li, Diagnostic value and prognostic evaluation of Presepsin for sepsis in an emergency department, Crit. Care 17 (2013) R244.

33. M. Behnes, T. Bertsch, D. Lepiorz, S. Lang, F. Trinkmann, M. Brueckmann, et al. Diagnostic and prognostic utility of soluble CD 14 subtype (presepsin) for severe sepsis and septic shock during the first week of intensive care treatment, Crit. Care 18 (2014) 507.

34. Masson S, Caironi P, Fanizza C, Thomae R, Bernasconi R, Noto A, et al. Circulating presepsin (soluble CD14 subtype) as a marker of host response in patients with severe sepsis or septic shock: data from the multicenter, randomized ALBIOS trial. Intensive Care Med. 2015 Jan; 41(1):12-20. doi: 10.1007/s00134-014-3514-2.

35. Zahorec: Ratio of neutrophil to lymphocyte counts - rapid and simple parameter of systemic inflammation and stress in critically ill. Bratisl Lek Listy 2001, 102:5-14.

\section{Tables}


Table 1. Baseline demographic characteristics

\begin{tabular}{|c|c|c|}
\hline$\overline{\text { Variable }}$ & & \\
\hline Age (years) & 74.0 & $(65.5-78.5)$ \\
\hline $\operatorname{Sex}(\mathrm{male})(\%)$ & 51.0 & $(61.4)$ \\
\hline Cancer (\%) & 40.0 & $(48.2)$ \\
\hline Coronary artery disease $(\%)$ & 4.0 & $(4.8)$ \\
\hline Diabetes mellitus (\%) & 10.0 & $(12.0)$ \\
\hline Hypertension (\%) & 21.0 & $(25.3)$ \\
\hline Albumin (g/dL) & 2.3 & $(1.8-3.0)$ \\
\hline $\mathrm{CRP}(\mathrm{mg} / \mathrm{dL})$ & 10.4 & $(3.7-17.5)$ \\
\hline $\operatorname{WBC}\left(\times 10^{9} 1^{-1}\right)$ & 10.9 & $(5.4-15.4)$ \\
\hline Neutrophil count $\left(\times 10^{9} \Gamma^{-1}\right)$ & 8.7 & $(3.56-13.29)$ \\
\hline Lymphocyte court $\left(\times 10^{9} 1^{-1}\right)$ & 0.5 & $(0.299-0.927)$ \\
\hline Plt count $\left(\times 10^{4} \mathrm{~mm}^{3}\right)$ & 17.8 & $(11.5-26.5)$ \\
\hline Fibrinogen (mg/dL) & 609.0 & $(378-711)$ \\
\hline Survival (dead) $(\%)$ & 26.0 & $(31.3)$ \\
\hline $\mathrm{AKI}(\%)$ & 38.0 & $(45.8)$ \\
\hline ARDS (\%) & 13.0 & $(15.7)$ \\
\hline Shock (\%) & 48.0 & $(57.8)$ \\
\hline DIC (\%) & 30.0 & $(36.1)$ \\
\hline Presepsin on Day $1(\mathrm{pg} / \mathrm{mL})$ & 1051.5 & $(569-1819.3)$ \\
\hline Presepsin on Day $2(\mathrm{ng} / \mathrm{mL})$ & 1016.5 & $(538-2156)$ \\
\hline Presepsin on Day $3(\mathrm{ng} / \mathrm{mL})$ & 802.0 & $(480.5-1825)$ \\
\hline Presepsin on Day $5(\mathrm{ng} / \mathrm{mL})$ & 1043.0 & $(480-1616)$ \\
\hline$\Delta$ Presepsin Day 2 - Day $1(\mathrm{pg} / \mathrm{mL})$ & -21.50 & $(-246.5-274.75)$ \\
\hline$\Delta$ Presep sin Day 3 - Day $1(\mathrm{pg} / \mathrm{mL})$ & -38.50 & $(-748.5-304)$ \\
\hline$\Delta$ Presepsin Day 5 - Day $1(\mathrm{pg} / \mathrm{mL})$ & -59.50 & $(-745.75-635.5)$ \\
\hline GPS & 1.0 & $(1-2)$ \\
\hline NLR & 12.6 & $(4.53-26.35)$ \\
\hline PLR & 321.9 & $(195.63-543.69)$ \\
\hline PI & 1.0 & $(1-2)$ \\
\hline PNI & 26.6 & $(21.26-33.72)$ \\
\hline SOFA & 8.0 & $(5-11)$ \\
\hline qSOFA & 2.0 & $(1-3)$ \\
\hline
\end{tabular}

CRP, C-reactive protein: WBC, white blood cell; $A K I$, acute kidney iniury, ARDS, acute re spiratory distre ss sndrome; DIC, disseminated intrava scular coagulation: GPS, Glasgow Prognostic Score; NLR, neutrophil to lymphocyte ratio; PLR, platelet to lymphocyte ratio; PI, Prognostic Index; PNI, Progno stic Nutritional Index; SOFA, Sequential Organ Fallure Assessment; qSOFA, quick Sequential Organ Failure Assessment 
Table 2. Predictors of septic AKI and RRT iritiation

\begin{tabular}{|c|c|c|}
\hline & $\mathrm{AKI}(\mathrm{n}=38)$ & RRT initiation $(\mathrm{n}=6)$ \\
\hline & Univariate analysis & Univariate analysis \\
\hline Variable & $P$-value & $P$-value \\
\hline Age & 0.402 & 0.108 \\
\hline Sex & 0.930 & 0.670 \\
\hline Cancer & 0.236 & 0.383 \\
\hline Coronary artery disease & 0.621 & none \\
\hline Diabetes mellitus & 0.005 & 0.620 \\
\hline Hypertension & 0.010 & 0.368 \\
\hline Albumin & 0.851 & 0.137 \\
\hline CRP & 0.023 & 0.773 \\
\hline WBC & 0.253 & 0.606 \\
\hline Neutrophil & 0.315 & 0.564 \\
\hline Lymphocytes & 0.631 & 0.127 \\
\hline Platelet count & 0.081 & 0.127 \\
\hline Fibrinogen & 0.427 & 0.088 \\
\hline Survival & 0.052 & 0.333 \\
\hline ARDS & 0.069 & 0.035 \\
\hline Shock & 0.080 & 0.641 \\
\hline DIC & 0.000 & 0.206 \\
\hline Presepsin on Day 1 & 0.001 & 0.149 \\
\hline Presepsin on Day 2 & 0.009 & 0.019 \\
\hline Presepsin on Day 3 & 0.143 & 0.905 \\
\hline Presepsin on Day 5 & 0.185 & 0.053 \\
\hline$\Delta$ Presep $\sin$ Day 2 - Day 1 & 0.810 & 0.032 \\
\hline$\Delta$ Presep $\sin$ Day 3 - Day 1 & 0.530 & 0.811 \\
\hline$\Delta$ Presep sin Day 5 - Day 1 & 0.408 & 0.053 \\
\hline GPS & 0.232 & 0.832 \\
\hline NLR & 0.969 & 0.837 \\
\hline PLR & 0.032 & 0.458 \\
\hline PI & 0.220 & 0.575 \\
\hline PNI & 0.696 & 0.091 \\
\hline iPS-GPS & 0.024 & 0.528 \\
\hline iPS-NLR & 0.203 & 0.217 \\
\hline IPS-PLR & 0.877 & 0.242 \\
\hline iPS-PI & 0.025 & 0.782 \\
\hline iPS-PNI & 0.172 & 0.718 \\
\hline SOFA & 0.024 & 0.200 \\
\hline qSOFA & 0.102 & 0.726 \\
\hline
\end{tabular}

$A K I$, acute kidney injury, RRT, renal replacement therapy, CRP, C-reactive protein; WBC, white blood cell; ARDS, acute respiratory distress syndrome; DIC, disseminated intravascular co agulation; GPS, Glasgow Progno stic Score; NLR, neutrophil to lympho cyte ratio; PLR, platelet to lymphocyte ratio; PI, Prognostic Index; PNI Prognostic Nutritional Index; PS, inflammation-presepsin score; SOF A, Sequential Organ F allure Assessment; qSOFA, quick Sequential Organ F ailure Assessment 
Table 3. Receiver operating characteristic curve analysis

\begin{tabular}{|c|c|c|c|c|c|}
\hline Variable & AUC & Cut-off & $P$ value & Sensitivity (\%) & Specificity $(\%)$ \\
\hline \multicolumn{6}{|l|}{ AKI } \\
\hline Presepsin on Day 1 (pgmL) & 0.73 & 708.00 & $\mathrm{P}<0.001$ & 81.6 & 58.5 \\
\hline Presepsin on Day 2 (pgmL) & 0.71 & 985.00 & 0.002 & 65.5 & 64.3 \\
\hline \multicolumn{6}{|l|}{ RRT initiation } \\
\hline Presepsin on Day 1 ( $\mathrm{pg} / \mathrm{mL})$ & 0.71 & 2014.00 & 0.155 & 66.7 & 83.3 \\
\hline Presepsin on Day 2 (pg mL) & 0.90 & 2867.00 & $\mathrm{P}<0.001$ & 75.0 & 91.7 \\
\hline Presepsin on Day 5 (pg/mL) & 0.96 & 3014.00 & $\mathrm{P}<0.001$ & 100.0 & 92.9 \\
\hline$\Delta$ Presepsin Day 2 - Day 1 (pgmL) & 0.84 & 507.00 & 0.002 & 75.0 & 80.0 \\
\hline$\Delta$ Presepsin Day 5 - Day 1 (pgmL) & 0.93 & 2385.00 & $\mathrm{P}<0.001$ & 1.0 & 93.3 \\
\hline PNI & 0.72 & 19.51 & 0.145 & 66.7 & 93.5 \\
\hline
\end{tabular}

$\overline{\mathrm{AUC}}$, area under the curve; AKI, acute kidney injury, RRT, renal replacement therapy, PNI, Prognostic Nutritional Index 
Table 4. Receiver operating characteristic curve analysis

\begin{tabular}{|c|c|c|c|c|c|}
\hline Variable & $\mathrm{AUC}$ & Cut-off & Pvalue & Sensitivity & Specificity \\
\hline \multicolumn{6}{|l|}{ 28-day mortality } \\
\hline Presepsin on Day $1(\mathrm{pg} / \mathrm{mL})$ & 0.77 & 1373.00 & 0.004 & 0.82 & 0.77 \\
\hline Presepsin on Day $2(\mathrm{pg} / \mathrm{mL})$ & 0.83 & 1581.00 & 0.000 & 0.86 & 0.68 \\
\hline Presepsin on Day $3(\mathrm{pg} / \mathrm{mL})$ & 0.91 & 1819.00 & 0.000 & 1.00 & 0.82 \\
\hline Presepsin on Day $5(\mathrm{pg} / \mathrm{mL})$ & 1.00 & 3014.00 & 0.000 & 1.00 & 1.00 \\
\hline$\Delta$ Presepsin Day 2 - Day $1(\mathrm{pg} / \mathrm{mL})$ & 0.76 & 507.00 & 0.059 & 0.71 & 0.86 \\
\hline$\Delta$ Presepsin Day 3 - Day $1(\mathrm{pg} / \mathrm{mL})$ & 0.91 & -10.00 & 0.000 & 1.00 & 0.76 \\
\hline$\Delta$ Presepsin Day 5 - Day $1(\mathrm{pg} / \mathrm{mL})$ & 0.79 & 2385.00 & 0.176 & 0.75 & 1.00 \\
\hline iPS-PLR & 0.75 & 1.00 & 0.002 & 0.91 & 0.46 \\
\hline \multicolumn{6}{|l|}{60 -day mortality } \\
\hline Presepsin on Day $1(\mathrm{pg} / \mathrm{mL})$ & 0.70 & 1373.00 & 0.063 & 0.75 & 0.76 \\
\hline Presepsin on Day $2(\mathrm{pg} / \mathrm{mL})$ & 0.73 & 1581.00 & 0.052 & 0.75 & 0.67 \\
\hline Presepsin on Day $3(\mathrm{pg} / \mathrm{mL})$ & 0.75 & 1819.00 & 0.134 & 0.80 & 0.81 \\
\hline Presepsin on Day $5(\mathrm{pg} / \mathrm{mL})$ & 0.80 & 3014.00 & 0.134 & 0.80 & 1.00 \\
\hline$\Delta$ Presepsin Day 2 - Day $1(\mathrm{pg} / \mathrm{mL})$ & 0.74 & 507.00 & 0.045 & 0.63 & 0.86 \\
\hline$\Delta$ Presepsin Day 3 - Day $1(\mathrm{pg} / \mathrm{mL})$ & 0.85 & -10.00 & 0.000 & 0.80 & 0.75 \\
\hline$\Delta$ Presepsin Day 5 - Day $1(\mathrm{pg} / \mathrm{mL})$ & 0.72 & 2385.00 & 0.238 & 0.60 & 1.00 \\
\hline iPS-PLR & 0.70 & 1.00 & 0.024 & 0.83 & 0.44 \\
\hline \multicolumn{6}{|l|}{ 90-day mortality } \\
\hline Presepsin on Day $1(\mathrm{pg} / \mathrm{mL})$ & 0.65 & 1373.00 & 0.142 & 0.64 & 0.74 \\
\hline Presepsin on Day $2(\mathrm{pg} / \mathrm{mL})$ & 0.65 & 1581.00 & 0.190 & 0.60 & 0.63 \\
\hline Presepsin on Day $3(\mathrm{pg} / \mathrm{mL})$ & 0.74 & 1545.00 & 0.085 & 0.83 & 0.73 \\
\hline Presepsin on Day $5(\mathrm{pg} / \mathrm{mL})$ & 0.79 & 1399.00 & 0.082 & 0.83 & 0.73 \\
\hline$\Delta$ Presepsin Day 2 - Day $1(\mathrm{pg} / \mathrm{mL})$ & 0.69 & 507.00 & 0.092 & 0.50 & 0.84 \\
\hline$\Delta$ Presepsin Day 3 - Day $1(\mathrm{pg} / \mathrm{mL})$ & 0.87 & -10.00 & 0.000 & 0.83 & 0.80 \\
\hline$\Delta$ Presepsin Day 5 - Day $1(\mathrm{pg} / \mathrm{mL})$ & 0.74 & 244.00 & 0.108 & 0.67 & 0.82 \\
\hline \multicolumn{6}{|l|}{ 180-day mortality } \\
\hline Presepsin on Day $1(\mathrm{pg} / \mathrm{mL})$ & 0.65 & 1336.00 & 0.121 & 0.67 & 0.68 \\
\hline Presepsin on Day $2(\mathrm{pg} / \mathrm{mL})$ & 0.68 & 1581.00 & 0.093 & 0.64 & 0.67 \\
\hline Presepsin on Day $3(\mathrm{pg} / \mathrm{mL})$ & 0.80 & 1545.00 & 0.019 & 0.86 & 0.79 \\
\hline Presepsin on Day $5(\mathrm{pg} / \mathrm{mL})$ & 0.77 & 1313.00 & 0.063 & 0.86 & 0.70 \\
\hline$\Delta$ Presepsin Day 2 - Day $1(\mathrm{pg} / \mathrm{mL})$ & 0.73 & 507.00 & 0.022 & 0.55 & 0.89 \\
\hline$\Delta$ Presepsin Day 3 - Day $1(\mathrm{pg} / \mathrm{mL})$ & 0.91 & -10.00 & 0.000 & 0.86 & 0.86 \\
\hline$\Delta$ Presepsin Day 5 - Day $1(\mathrm{pg} / \mathrm{mL})$ & 0.76 & -23.00 & 0.051 & 0.71 & 0.80 \\
\hline
\end{tabular}

$\mathrm{AUC}$, area under the curve; iPS, inflammation-presep sin score; PLR, platelet to lymphocyte ratio 


\begin{tabular}{|c|c|}
\hline Variable & P value \\
\hline \multicolumn{2}{|l|}{ 28-day mortality } \\
\hline Presepsin on Day 1 (pg/mL) & 0.00 \\
\hline Presepsin on Day $2(\mathrm{pg} / \mathrm{mL})$ & 0.086 \\
\hline Presepsin on Day $3(\mathrm{pg} / \mathrm{mL})$ & 0.126 \\
\hline Presepsin on Day $5(\mathrm{pg} / \mathrm{mL})$ & 0.002 \\
\hline$\Delta$ Presepsin Day 2 - Day $1(\mathrm{pg} / \mathrm{mL})$ & 0.014 \\
\hline$\Delta$ Presepsin Day 3 - Day $1(\mathrm{pg} / \mathrm{mL})$ & 0.093 \\
\hline$\Delta$ Presepsin Day 5 - Day $1(\mathrm{pg} / \mathrm{mL})$ & 0.008 \\
\hline PNI & 0.001 \\
\hline PPS - PLR & 0.036 \\
\hline \multicolumn{2}{|l|}{60 -day mortality } \\
\hline Presepsin on Day 1 (pg/mL) & 0.007 \\
\hline Presepsin on Day $2(\mathrm{pg} / \mathrm{mL})$ & 0.170 \\
\hline Presepsin on Day $3(\mathrm{pg} / \mathrm{mL})$ & 0.367 \\
\hline Presepsin on Day 5 (pg/mL) & 0.003 \\
\hline$\Delta$ Presepsin Day 2 - Day $1(\mathrm{pg} / \mathrm{mL})$ & 0.026 \\
\hline$\Delta$ Presepsin Day 3 - Day $1(\mathrm{pg} / \mathrm{mL})$ & 0.223 \\
\hline$\Delta$ Presepsin Day 5 - Day $1(\mathrm{pg} / \mathrm{mL})$ & 0.009 \\
\hline PNI & 0.003 \\
\hline \multicolumn{2}{|l|}{90 -day mortality } \\
\hline Presepsin on Day 1 (pg/mL) & 0.056 \\
\hline Presepsin on Day $2(\mathrm{pg} / \mathrm{mL})$ & 0.788 \\
\hline Presepsin on Day $3(\mathrm{pg} / \mathrm{mL})$ & 0.212 \\
\hline Presepsin on Day 5 (pg/mL) & 0.226 \\
\hline$\Delta$ Presepsin Day 2 - Day 1 (pg/mL) & 0.090 \\
\hline$\Delta$ Presepsin Day 3 - Day $1(\mathrm{pg} / \mathrm{mL})$ & 0.091 \\
\hline$\Delta$ Presepsin Day 5 - Day $1(\mathrm{pg} / \mathrm{mL})$ & 0.072 \\
\hline \multicolumn{2}{|l|}{ 180-day mortality } \\
\hline Presepsin on Day $1(\mathrm{pg} / \mathrm{mL})$ & 0.079 \\
\hline Presepsin on Day 2 (pg/mL) & 0.798 \\
\hline Presepsin on Day $3(\mathrm{pg} / \mathrm{mL})$ & 0.128 \\
\hline Presepsin on Day $5(\mathrm{pg} / \mathrm{mL})$ & 0.265 \\
\hline$\Delta$ Presepsin Day 2 - Day $1(\mathrm{pg} / \mathrm{mL})$ & 0.038 \\
\hline$\Delta$ Presepsin Day 3 - Day $1(\mathrm{pg} / \mathrm{mL})$ & 0.029 \\
\hline$\Delta$ Presepsin Day 5 - Day $1(\mathrm{pg} / \mathrm{mL})$ & 0.057 \\
\hline
\end{tabular}


Table 6. Predictors of mortality in sepsis patients (univariate analysis)

\begin{tabular}{|c|c|c|c|c|}
\hline & 28-day mortality & 60-day mortality & 90-day mortality & 180-day mortality \\
\hline Variable & $P$-value & $P$-value & $P$-value & $P$-value \\
\hline Age & 0.4744 & 0.6260 & 0.3081 & 0.4572 \\
\hline Sex & 0.7277 & 1.0000 & 1.0000 & 0.7341 \\
\hline Cancer & 0.1691 & 0.3193 & 0.4979 & 0.7384 \\
\hline Coronary artery disease & 1.0000 & 1.0000 & 1.0000 & 1.0000 \\
\hline Diabetes mellitus & 0.2293 & 0.2204 & 0.4339 & 0.2616 \\
\hline Hypertension & 0.4657 & 0.2863 & 0.7379 & 0.5144 \\
\hline Albumin & 0.1570 & 0.4257 & 0.2720 & 0.5150 \\
\hline CRP & 0.1579 & 0.0535 & 0.1068 & 0.1417 \\
\hline WBC & 0.4156 & 0.4654 & 0.9625 & 0.8406 \\
\hline Neutrophil & 0.4252 & 0.3468 & 0.8510 & 0.9753 \\
\hline Lymphocytes & 0.3352 & 0.7212 & 0.7541 & 0.9261 \\
\hline Platelet count & 0.1183 & 0.2699 & 0.3721 & 0.3147 \\
\hline Fibrinogen & 0.0019 & 0.0019 & 0.0026 & 0.0043 \\
\hline ARDS & 0.1249 & 0.0486 & 0.1322 & 0.2578 \\
\hline Shock & 0.7217 & 0.7110 & 0.7351 & 0.7235 \\
\hline DIC & 0.2847 & 0.4912 & 1.0000 & 1.0000 \\
\hline Presepsin on Day 1 & 0.0115 & 0.0556 & 0.1368 & 0.1257 \\
\hline Presepsin on Day 2 & 0.0093 & 0.0570 & 0.1909 & 0.1105 \\
\hline Presepsin on Day 3 & 0.0122 & 0.0986 & 0.0868 & 0.0305 \\
\hline Presepsin on Day 5 & 0.0032 & 0.0578 & 0.0562 & 0.0637 \\
\hline$\Delta$ Presepsin Day 2 - Day 1 & 0.0415 & 0.0454 & 0.1033 & 0.0366 \\
\hline$\Delta$ Presepsin Day 3 - Day 1 & 0.0122 & 0.0208 & 0.0102 & 0.0028 \\
\hline$\Delta$ Presepsin Day 5 - Day 1 & 0.0894 & 0.1706 & 0.1078 & 0.0790 \\
\hline GPS & 0.5179 & 0.2002 & 0.5073 & 0.7101 \\
\hline NLR & 0.3030 & 0.1194 & 0.3638 & 0.4036 \\
\hline PLR & 0.7649 & 0.7952 & 0.8756 & 0.5990 \\
\hline PI & 0.1751 & 0.1579 & 0.6093 & 0.9329 \\
\hline PNI & 0.0911 & 0.4362 & 0.3014 & 0.5777 \\
\hline iPS-GPS & 0.1270 & 0.3206 & 0.3377 & 0.3436 \\
\hline iPS-NLR & 0.1220 & 0.2898 & 0.2913 & 0.4036 \\
\hline iPS-PLR & 0.0100 & 0.0365 & 0.0840 & 0.1932 \\
\hline iPS-PI & 0.2891 & 0.5490 & 0.3714 & 0.2989 \\
\hline iPS-PNI & 0.7178 & 0.1765 & 0.4710 & 0.5194 \\
\hline SOFA & 0.8806 & 0.6250 & 0.3067 & 0.4653 \\
\hline qSOFA & 0.8457 & 0.5805 & 0.2173 & 0.4010 \\
\hline
\end{tabular}

CRP, C-reactive protein; WBC, white blood cell; AKI, acute kidney injury; ARDS, acute respiratory distress syndrome; DIC, disseminated intravascular coagulation; GPS, Glasgow Prognostic Score; NLR, neutrophil to lymphocyte ratio; PLR, platelet to lymphocyte ratio; PI, Prognostic Index; PNI, Prognostic Nutritional Index; iPS, inflammation-presepsin score; SOFA, Sequential Organ Failure Assessment, qSOFA, quick SequentialOrgan Faihure A ssessment 
Table 7. Multivariate lo gistic regression analysis

\begin{tabular}{|c|c|c|c|c|}
\hline Variable (examined explanatory variable) & Odds ratio & \multicolumn{2}{|c|}{$95 \% \mathrm{CI}$} & $P$ value \\
\hline \multicolumn{5}{|c|}{ 28-day mortality (Presep sin on Day 1, Presep sin on Day 2) } \\
\hline Presepsin on Day 1 & 0.9989 & 0.9974 & 1.0003 & 0.120 \\
\hline Presepsin on Day 2 & 1.0018 & 1.0002 & 1.0034 & 0.027 \\
\hline \multicolumn{5}{|l|}{ 28-day mortality (Presepsin on Day 1, ,PS-PLR) } \\
\hline Presepsin on Day 1 & 1.0004 & 0.9998 & 1.0010 & 0.182 \\
\hline PSS-PLR & 3.1006 & 0.7548 & 12.7370 & 0.116 \\
\hline \multicolumn{5}{|c|}{ 60-day mortality (Presep sin on Day 1, Presep sin on Day 2) } \\
\hline Presepsin on Day 1 & 0.9989 & 0.9975 & 1.0003 & 0.132 \\
\hline Presepsin on Day 2 & 1.0015 & 1.0001 & 1.0028 & 0.039 \\
\hline \multicolumn{5}{|l|}{ 60-day mortality (Presepsin on Day 1, IPS-PLR) } \\
\hline Presepsin on Day 1 & 1.0003 & 0.9998 & 1.0009 & 0.217 \\
\hline PS-PLR & 2.1516 & 0.5980 & 7.7414 & 0.241 \\
\hline \multicolumn{5}{|c|}{ 90-day mortality (Presep sin on Day 1, Presep sin on Day 2) } \\
\hline Presep sin on Day 1 & 0.9991 & 0.9978 & 1.0004 & 0.172 \\
\hline Presepsin on Day 2 & 1.0011 & 0.9998 & 1.0023 & 0.086 \\
\hline \multicolumn{5}{|c|}{ 180-day mortality (Presepsin on Day 1, Presepsin on Day 2) } \\
\hline Presepsin on Day 1 & 0.9987 & 0.9972 & 1.0002 & 0.078 \\
\hline Presepsin on Day 2 & 1.0015 & 1.0001 & 1.0029 & 0.037 \\
\hline
\end{tabular}

$\mathrm{CI}$, confidence interval; $\mathbb{P S}$, inflammation-presepsin Score; PLR, platelet to lvmphocyte ratio 